\title{
RESCUING IGBO LANGUAGE FROM ENDANGERMENT: THE ROLE OF LIBRARY AND INFORMATION TECHNOLOGIES
}

\author{
Nwaoke, Emmanuel Emeka \\ Department of Linguistics and Literary Studies, \\ Ebonyi State University, Abakaliki Ebonyi State, Nigeria \\ nwaokebest@gmail.com \\ 08061109362 \\ DOI: 10.31364/SCIRJ/v7.i4.2019.P0419641 \\ http://dx.doi.org/10.31364/SCIRJ/v7.i4.2019.P0419641
}

\begin{abstract}
Igbo as an endangered language can be rescued from language death. Language documentation is the answer to its endangerment since it helps in preserving and stabilizing the lexicon, grammar and oral tradition of a language and a people. The purpose of this research is to x-ray the importance of Library and Information (and Communication) Technologies in documentation, revitalization and promotion of Igbo language in order to overcome all forms of endangerment. This paper reviewed and examined the role of library as an information storehouse and the significant role of ICT infrastructures in documentation, development and management of Igbo language resources. The study revealed that Igbo language can be documented through libraries and ICT supports. The library functions as a language repository and through the use of Information Communication Technologies (ICTs), access to Igbo language materials and other library resources in print and electronic forms would be easier and faster for a greater number of people. This makes the Igbo language materials readily available for everyone notwithstanding their geographical locations; hence the materials for Igbo language acquisition and learning will be easier and affordable. The study postulates that though UNESCO stated that Igbo language would be in extinction in no distant time, that through Igbo language documentation, library contributions and the use of ICTs by individuals and cooperate organizations as well as establishment of Igbo language documentation centres for print and virtual/digital resources and availability of such materials for public use, such prediction of extinction and its consequences would die naturally.
\end{abstract}

Keywords: Igbo language, endangerment, language documentation, library, ICT

\section{Introduction}

Igbo language is one of the three languages recognized as regional languages by Nigeria's language policy. It is the regional language for the South Eastern region of Nigeria with over 16million speakers (Federal Republic of Nigeria, 2007). Igbo language functions as a tool for cultural revival, research, teaching and learning of Igbo language in academic institutions and in the world at large. In virtually all the community in South Eastern Nigeria, Igbo is the language of tradition and cultural communication in the all sorts of formal and informal gatherings. "It is learned at home, schools, and colleges and in tertiary institutions, but today it is being feared of extinction due to the inversion of Western culture and the attitudes of Ndiigbo towards the language" (Asogwa B. E. \&Asogwa M. N., 2014). This attitude is not too far from the assertion of Nweze, I. M., Nwaoke, E. E. and Ikegwonu, C. N. (2019) when they aver that most languages of the world are currently going into extinction because of the interest people have in other languages that give them 
greater opportunity in gaining access to wealth and establishment of cordial relationship amongst people, speech communities and states.

Any ethnicity or tribe that loses her language has lost her culture, respect, wisdom, exposure, identity and lineage. Language can be preserved the same way people preserve their wealth. Language can grow, it can die or go into extinction (Nweze, Nwaoke \& Ikegwonu, 2019). UNESCO states that Igbo language is endangered. A language is endangered when the language is in the process of dying; according to Crystal (2000), a dead language is one which has no speakers. Campbell (1994) defined language death as "the loss of a language due to gradual shift to the dominant language in language contact situations". In the case of Nigeria's language condition and the National Language Policy, English appears to be the dominant language while the indigenous languages (Igbo inclusive) are seen as minor. Ayodele, (2013) is of the view that both indigenous and foreign languages are indispensable tools in the life of individuals because there is no aspect of human activities that can be successful without the effective use of language. This implies that when the people lose their language, they lose their destiny and success; hence there is need for revitalization, development and documentation of Igbo language. In line with above, Emeka-Nwobia (2015) states that the identity of a people and their way of life is enclosed in their language and same is also transmitted to other people and their newer generations through the use of language. Therefore, language serves as a means of accessing human thoughts, means of showing social relations, and means of transferring series of belief and life-style to a younger generation. If we lose the Igbo language, we do not only lose a means of communication but also means of social interaction and recording information. This formal mean of communication, social relation and information storage can be documented and preserved in real and virtual libraries for easier access. Onwubiko and Uzoigwe (2004) defined library as "an information center located in an organization, institution, industry, government or agencies to satisfy the information needs of the individual client and the realization of the broad objectives of the parent organization". They also observed that the role of libraries depend on the needs of the sponsoring organization or institution. This paper functions as an urgent call for all Igbos and Igbo language lovers/learners to contribute in shunning all forms of endangerment traits connected to Igbo language. This would be achieved by establishing individual, academic or public, real or virtual libraries that champion documentation of Igbo language. "Today, computers have become part of modern libraries, for space economy, accuracy and speed" (Nwankwegu \& Nwode 2012). This implies that the effectiveness of modern libraries (digital/virtual libraries) relies mainly on Information and Communication Technologies such as computers and other multimedia technologies which would make print and electronic material easily accessible to the world. Through this way, Igbo language users and learners at home and those in diasporas, young and adult, would have the opportunity to access the language materials without much stress. 


\section{Igbo as an endangered language}

"Towards the end of 2006, the United Nations made a prediction that some minor languages of the world will go extinct in the next 50 years. On this list was the Igbo language spoken in the Southeastern Nigeria by over 20 million people" (Asonye, 2013). Hence, the Igbo language is seen as an endangered language. The most painful aspect of this reality is that some Nigerian parents still believe that communicating with children in a foreign language is a mark of elitism (Oni, 2011). This is supported by Eme, C.A. (2004) when she stated that "Some Igbo parents, especially the literate ones, do not speak Igbo to their children even at home. In some cases, the parents ban their children from using Igbo to communicate among themselves.” Nwadike, I. U. (2008) added that many Igbo parents do not want their children to speak Igbo. He cited the case of an Igbo mother at the University of Nigeria, Nsukka, who once asked her children to desist from speaking that useless language (Igbo). This class of parents, according to him, gets offended with teachers who teach Igbo as a subject to their children.

UNESCO (2003) describes an endangered language as one that heads towards extinction. Aikawa in UNESCO (2001) ranks language endangerment under the five following category: (a) extinct endangerment(b) critically endangered (c) severely endangered (d) definitely endangered and (e) unsafe. The extinct category of language endangerment is seen in a situation where there is no one that speaks or remembers the language; this simply implies that the language has no speakers and has no documentation at all for reference purpose. A language is critically endangered when it is spoken by few members of the oldest generation and cannot be transferred to a large number of the younger generation because it is not used for everyday interactions. A severely endangered language is one spoken only by the supposed oldest generation of a speech community and few other members of the generations and the younger generation would not have the privilege to acquire or learn the language. When it is definitely endangered, the language is no longer acquired or learned as the mother tongue by children in the speech community hence it is hardly used in their daily transactions or interactions. However, a language is unsafe when most children in the speech community speak the language as their mother tongue but its use may be restricted or limited to some specific social domains; in that case the language may be used only in informal situations.

The Igbo language's situation currently could rightly be said to be unsafe since some children of the Igbo tribe are consciously and unconsciously restricted from using it in formal situation. Most of these children are taught in schools even in their tender age using the English language. Ayeomoni (2011) states that language being a means through which individuals share ideas, experiences, emotions, and interact is an important tool in the society. And the Igbo language has been denied the opportunity to this and this could be the reason Oyelami, O. M. (2008) affirmed that Igbo language is one of the languages that has been stated to be in endangerment and that the language could be saved from such problem if the Igbo teachers and learners promote the teaching and learning of the Igbo language by using audio-visual electronic devices, the ICTs, and the internet for wider coverage and easier access. All aspects of 
human endeavour,be it developmental, intellectual, ethical, political, social or economical requires the use of language (Ene, 2007) hence, there is urgent need for promotion and revitalization of Igbo language.

\section{Promotion, preservation and revitalization of Igbo language}

There is urgent need for promotion, preservation and revitalization of Igbo language. Igbo language should be popularized amongst the speakers and language scientists. It is part of Igbo heritage and should be preserved and revitalized. Ezema, T. O., Nzeagwu, M., Ede, C., Silvanus, M. A., Ugwuede, G. E. and Anaekwe, R. C. (2018) states that "Igbo language and other Nigerian languages (NLs) have been suffering a lot of setback both in their use as medium of instruction and their studies in secondary school, due to lack of material resources". Hence these materials can be made readily available when they are properly documented in both print and electric/virtual forms. Iloene, M. I., Iloene, G. O., Mbah, E. E. and Mbah, B. M. (2013) carried out a research on how to teach the Igbo language using computer and other modern instructional materials. There research centered on two universities where they discovered that computers and some of the modern instructional aides are readily available with competent hands but one of the major problems faced by these institutions is that most of the computers do not have the software for encoding and decoding of Igbo language. They suggest that recent researches and invention in language related technology should take cognizance of Igbo writing system and the writing system of other languages of the world. Hence it revealed that the English language has taking over almost everything thereby leaving Igbo and some other world languages in endangered condition. Ene (2007) posits that instead of making a foreign language enjoy the states it is enjoying presently, indigenous languages (Igbo inclusive) and courses in teacher education institutions should be planned to equip every teacher with the capacity of teaching in both foreign and indigenous languages. This according to Alhassan and Ali (2015) is very important to the meaningful existence of human race since language is used by man as a means of social interaction, cultural transmission, advancement of knowledge and educational development. Nwankwere A.U.. N., Mmadike B. I. and Eme C. A. (2017) posit that the survival of Igbo language is in the hands of the Igbo parents and Igbo children. They argue that if parents especially those in diasporas use Igbo language in their daily activities and in their respective homes, it would give their children the opportunity to acquire/learn the language. They also stated that it is the responsibility of every Igbo to see that the Igbo language is transferred from one generation to another so as to avoid every form of endangerment. It is obvious that if the Igbo race looses the Igbo language, they automatically lose their identity as a people: Igbo is Igbo; the language and the people are inseparable. Adzer (2012) supports the above assertion when he said that the survival of the language of a people is very vital to the people's survival on the whole. Hence this research functions as a reminder to the Igbo people to protect, promote, preserve and revitalize their own language which in turn protects their culture and identity as a people.

\section{The use of ICTs and library in documentation of Igbo language}

Within the discipline of linguistics, Language Documentation has been found to be a lasting solution to language endangerment. Austin (2010) stated that language documentation can also be called documentary linguistics. He avers that this subfield of linguistics www.scirj.org 
is multi-disciplinary and added that documentary linguistics and descriptive linguistics cross-fertilizes each other. Himmelmann (2006) described this sub-area of linguistic study as one which is 'concerned with the methods, tools, and theoretical underpinnings for compiling a representative and lasting multipurpose record of a natural language or one of its varieties. It is a rapidly emerging new field in linguistics and related disciplines working with little-known speech communities'. Woodbury (2010) complemented the above assertion when he defined the subfield as 'the creation, annotation, preservation, and dissemination of transparent records of a language'. Documentary linguistics according Austin (2007) and Whalen (2004) as quoted by Austin (2010) "has developed over the past 15 years in response to the need to make a lasting record of the world's endangered languages (estimated to be as many as $90 \%$ of the 7,000 languages spoken on earth today), and to support speakers of these languages in their desires to maintain them". According to Himmelmann(2006), there are basically three reasons for engaging in language documentation and they are language endangerment, the economy of research resources, and accountability. Therefore, it is obvious that the idea of documentary linguistics was introduced as a result of languages going into extinction.

Once there is proper documentation and preservation of a language (Igbo language for instance), such language cannot die. Language documentation also helps in the maintenance of cultural diversity. The library is a key player in achieving this goal since it is a reliable domain for recording thoughts, experiences, history, culture and heritage in language and to make it available to others (Olaifa, T. P. 2014). Language Documentation $\mathrm{x}$-rays the beauty and richness of language. It is a means through which the values, experiences, stories and artifacts of a speech community can be preserved and it is also encourages the growth and development of language. The world is dynamic and also going global; the emergence of the Information Technology into the Nigerian System is capable of leading many Nigerian indigenous languages to go into extinction beyond expectation. (Njamanze, 2008).Information Technology according to Marshall (1984), is the coming together of computing and telecommunications for the purpose of handling information; the application of technologies to information handling; including generation, storage, processing, retrieval and dissemination. Information technology is of great importance in language documentation especially in mobilization. The term mobilization refers to standardization of data and metadata formats. It is an idea that portrays that the formats for documentation of data and meta-data should not exhaust the contribution that information technology can make to endangered languages data (Nathan, 2003). The primary data refers to the major files of language documentation which includes audio or video recordings of a communicative event such as narratives and conversations. Others are notes taken in an elicitation session and genealogy written down by literate native speakers of the language documented. These primary data, according to Himmelmann (2006), summarily referred to as the "apparatus", are compiled in a structured corpus and they have to be made accessible by various types of annotations and commentary. Data about data is called metadata. They are structured information about events, recordings, and data files. Most often, they are represented as text and are stored based on some formal specification (Bird \& Simons 2003). 
The metadata on the other hand, have two interrelated functions on both levels. Firstly, just like library cataloguing, they facilitate access to documentation or a specific record within a set of documented files by providing key access information in a standardized format. It displays the type of file, where and how it can be accessed and other key pieces of information about the documented file. The second is organizational function: this defines the structure and standard of the corpus in the case of documentations in digital format through which searching, copying, or filtering of files within a single documentation or across a set of documentations is done. This second function has to be richer and more elaborate than one which targets the cataloguing function. The first function is actually a corpus management tool, which defines digital structures and supports various computational procedures while the second is a standard for organizing a catalogue. (Himmelmann, 2006)."Metadata is structured data about data - descriptive information about a physical object or a digital resource. Library card catalogs represent a well-established type of metadata, and they have served as collection management and resource discovery tools for decades" (Bird, S. \& Simons, G. 2003).

From his description about the mobilization, metadata and interrelated functions of metadata, it is obvious that library and ICT infrastructures cannot be ignored in proper documentation of the Standard Igbo language and her dialects and that is why Woodbury (2003), rightly said that "We should be able to link transcriptions with audio and videotapes, and entries and dictionaries or statements in grammars with large databases of illustrative examples".

Igbo language is supposedly the commonest means of communication among the settlers in South Eastern Nigeria. In line with Dooga (2012) which states that the loss of a language includes the loss of a people's heritage, culture and national history, it would be extremely bad if the Igbo language goes into extinction since it is one of the three key indigenous national languages in Nigeria. The Igbos and linguists should do their best to help in saving this language through every possible means especially through the help of virtual library infrastructures and Information and Communication Technologies (ICTs). The influence of Information and Communication Technologies (ICTs) is now common in every sphere of human endeavour including the Library and Information Science (LIS) field which is considered as pervasive (Kumar, 2014). Etebu (2010) asserts that without useful help of Internet facilities, librarians will not be helpful to their clients. One can give what one does not have; it is only skilled librarians that can teach their clients the use of the Internet and World Wide Web in navigation of library electronic materials.

The general objective of this paper is to discover how the use of Information Communication Technology (ICT) and Library would help in documenting and safeguarding Igbo language. To this end, Olafia (2014) states that, many societies are faced with the challenges of language loss, language shift or even language death and that this is linked to the fact that a large percentage of the languages are still not properly documented. Igbo language documentation is very important especially at this point in history of the Igbos. Balogun (2013) contends that the loss of any language by a people is the loss of their root and their identity. He added that when a people lose their language they live in the shadow of other people's identity and culture. 
When we talk of Igbo, we actually mean a people and their language; hence a real Igbo person is one who understands and speaks Igbo language. Abdulsalami, Okezie and Agbo (2013) state that the need for the preservation of knowledge and dissemination of information led to the establishment of more and more libraries.Ikoku (1971) described library as the foyer of living ideas. He added that ideas permeate and animate all aspect of national life; library is a place where the dead are alive, where the ideas, knowledge and experience of great men though dead continue to live. Thus libraries are of great importance to the knowledge of every society. Rajkoomar (2012) support the above assertions when he stated that a library is a treasure-house of knowledge which is important for man for preserving and maintaining the valuable knowledge, information and wisdom contained in books and documents because of their need for the coming generations.

Language can be documented electronically in form of audio files/books, audio-visual file and in any other electronic or digital form. The idea of digital storage according to Ndukwe (2007) emanated from the practical effects of technological convergence. Digital storage is the collation and storing of information, physically or electronically, by sorting, scanning, and/or archiving in an accessible and retrievable form that would stand the test of time. (Njameze, 2008).

From various researches by many scholars Information Technology is considered in the library to be concerned with acquisition, processing, storage and dissemination of information - textual, numerical, pictorial and vocal. In other words, it is considered as a broad-based term comprising the gathering (acquisition), organization (packaging), storage and retrieval (dissemination) of information that can be in textual or numerical (books, documents), vocal and pictorial forms (audio-visual) or a combination of all the above (multimedia), using a combination of computer and telecommunications devices (Fagbe, Amanze, Oladipo, Oyenuga \& Adetunji, 2015).

\section{Conclusion and recommendations}

Igbo as a regional language of the South Eastern Nigeria has been found to be unsafe: most Igbo children acquire it as their mother tongue but are restricted in their formal use of the language. Hence they use it mostly in informal settings thereby weakening its functions as a tool for cultural revival, research, teaching and learning. Looking at the multilingual nature of Nigeria, English language and other indigenous languages are indispensable tools in the life of Nigerians because there is no aspect of human activities that can be successful without the effective use of language. We advocate for Igbo language documentation through the use of library and information technologies for easier access to Igbo language instructional and recreational materials. This would be achieved by establishing individual, academic or public, digitalized libraries that uphold real or virtual documentation of Igbo language. The resource data and metadata would be handled, stored and processed in the libraries while same can be retrieved or disseminated through the use of ICT infrastructures. And through this method, Igbo language users and learners not minding their age or location would have access to language materials and other data that promote Igbo language and other forms of Igbo heritage without much 
stress. We also recommend that more researches should be conducted in this area especially the ones that reveal the journey of Igbo language documentation and its recorded success or challenges.

\section{References}

Abdulsalami, L. T. ,Okezie, Q. I. \& A. D. Agbo (2013) The role of the library in the promotion of knowledge societies in Nigeria Pelagia Research Library Advances in Applied Science Research, 2013, 4(1):58-70

Adzer, V. C. (2012). Factors militating against the development of indigenous languages: The TIV language in perspective. Journal Of Igbo Language \& Linguistics, 5; 76-79.

Aikawa, N. (2001). UNESCO's programme on languages. Conference handbook on endangered languages of Pacific rim. Pp. 13 - 24. Osaka: Endangered Languages of the Pacific Rim Project

Akabogu, J. U. \&Mbah, B. M. (2013). Second language acquisition, attrition of indigenous languages in Nigeria: cultural implications, 13(4):1-5.

Alhassan, H. O. \& Ali, A. K. (2015). Reviving indigenous languages through teaching and learning: the case of Igala language International Journal of Education, Learning and Development, 3(7):35-46.

Asogwa, B. E. \& Asogwa, M. N. Information and communication technologies and Igbo studies in tertiary institutions in Nigeria: issues and challenges. Library philosophy and practice e-journal https://digitalcommons.unl.edu/cgi/viewcontent.cgi? article=3084\&context=libphilprac

Asonye, E. (2013) UNESCO Prediction of the Igbo Language Death: Facts and Fables Journal of the Linguistic Association of Nigeria Volume 16 Nos. 1 \& 22013 (pp. 91-98) http://www.academix.ng/documents/papers/1463491669_1870.pdf

Austin, P. K. (2006). Data and language documentation.In Jost Gippert, Nikolaus Himmelmann and Ulrike Mosel (eds.) Essentials of Language Documentation (Trends in Linguistics.Studies andMonographs, 178), 87-112. Berlin: Mouton de Gruyter. http://emilkirkegaard.dk/lyddansk/sites/default/files/files/essentials-of-language-documentation.pdf

Austin, P. K. (2010). Current issues in language documentation.In Peter K. Austin (ed.) Language Documentation and Description, vol 7. pp. 12-33 London: SOAS.

Ayeomoni, M. O. (2011). Migration and culture: Implications on Nigerian languages. Internal Journal of English and Literature, 2(9):195-199.

Ayodele, O. A. (2013). Language education: catalyst for promoting social stability, national security and conflict resolution in Nigeria. Journal of ELT and Poetry, 1(1)1-9.

Balogun, T. A. (2013). An endangered Nigerian indigenous language: The case of Yoruba language. African Nebula, 6; 70-82.

Bird, S. \& Simon, G. (2003) Seven dimensions of portability for language documentation and description. Language 79(3):55782.http://www.language-archives.org/documents/portability.pdf

Crystal, D. (2000) Language Death. Cambridge: Cambridge University Press.

Dooga, J. T. (2012). Nigerian languages: failing health and possible healing AFRREV LALIGENS, 1(1):76-95.

Emeka-Nwobia, N. U. (2015). The place of indigenous Nigerian languages in National development.Research on Humanities and Social Sciences 5 (12):112-116.

Ene, I. O. (2007). Nigerian language policy: Implication for teacher education in the education reform agenda. In: Nworgu, B. G. (ed). Optimization of service delivery in the education sector: Issues and strategies. (pp.179-183). Nsukka: University Trust Publishers. 
Etebu, A. T. (2010). ICT availability in Niger Delta university libraries

Ezema, T. O., Nzeagwu, M., Ede, C., Silvanus, M. A., Ugwuede, G. E. \&Anaekwe, R. C. (2018) An Appraisal of Igbo Language Teaching Material Resources in Secondary Schools in Niger State. International Journal of Strategic Research in Education, Technology and Humanities IJSRETH Volume 5, Number 1

Fagbe, A. O., Amanze, R. C., Oladipo, S., Oyenuga, E. \&Adetunji, O. O. (2015) The role of information technology in the academic library: A paper presented at the $3^{\text {rd }}$ School of Education and Humanities International Conference on the future of higher education in Africa held at Babcock University on August 24 - 26, 2015

https://www.babcock.edu.ng/oer/conference/THE\%20ROLE\%20OF\%20INFORMATION\%20TECHNOLOGY\%20\%28IT\% 29\%20IN\%20THE\%20ACADEMIC\%20LIBRARY.pdf

Federal Republic of Nigeria (2007) Official Gazette, 24 (94) Lagos, $15^{\text {th }}$ May.

Himmelmann, N. P. (2006) Language documentation: What is it and what is it good for?In JostGippert, NikolausHimmelmann and Ulrike Mosel (eds.) Essentials of Language Documentation (Trends in Linguistics.Studies andMonographs, 178), 1-30. Berlin: Mouton de Gruyter.

Ikoku, R. (2012) Special Libraries Retrieved from http://www//ifla.org/iv.ifla/64/134.88e.htm.

Iloene, M. I., Iloene, G. O., Mbah, E. E., \& Mbah, B. M. (2013). The use of new technologiesfor the teaching of the Igbo Language in schools: challenges and prospects. In L. Bradley \& S. Thouësny (Eds.), 20 Years of EUROCALL: Learning from the past, looking to the future. proceedings of the 2013 EUROCALL conference, Evora, Portugal (pp. 117-122). Dublin/Voillans

Kumar, A. (2014) "Students opinion about the success of mobile technology in libraries: A case study of Jawaharlal Nehru University (JNU), New Delhi", New Library World, Vol. 115 Issue: 9/10, pp.471-481, https://doi.org/10.1108/NLW-10-2013-0075

Marshall, C. (1984). Beginner's Guide to Information on Technology. London: Butterworth \& Co (Publishers) Ltd

Nathan, D. (2003). Endangered languages documentation: From standardization to mobilization. Paper presented at Digital resources for the Humanities 2003. University of Gloucestershire, September 2003.

Nathan, D. (2006). Thick interfaces: mobilizing language documentation with multimedia. In Jost Gippert, Nikolaus Himmelmann and Ulrike Mosel (eds.) Essentials of Language Documentation (Trends in Linguistics.Studies andMonographs, 178), 363-379. Berlin: Mouton de Gruyter.

Njamanze, Q. U. (2008). Documentation of endangered language via ICT: An assessment of the "Owerri /Igbo" language. International Journal of Development and Management Review (INJODEMAR) Vol. 3 No. 1

Nwadike, I.U. (2002). Igbo language in education: An historical study. Obosi: Pacific Publishers

Nwankwegu J. A. \& Nwode, G. C. (2012) Effective use of English. Enugu: De-envoy Media/Keny and Brothers

Nwankwere A.U. N., Mmadike B. I. \&Eme C. A. (2017) Safeguarding the Igbo language through teaching Igbo children in diaspora. http://dx.doi.org/10.4314/og.v13i 1.9

Nweze, I. M., Nwaoke, E. E. \& Ikegwonu, C. N. (2019).NkwaliteAsụsụ Igbo: Ileba Anya naNsụgharị .Ékwe jọnal nke ndị Igbo scholars forum, Nigeria Volume 12; No 1http://www.igboscholarsforum.com.ng/649-2/

Olaifa, T. P. (2014). Language preservation and development: the role of the library. Journal of Library and Information Sciences, 2(1): $23-28$.

Oni, Duro (2011, Thursday, March 3). Preservation and revival of Nigerian cultural heritage, In Daily Sun 6(2003), 38

Onwubiko, E. C. N. \& Uzoigwe, C. U. (2004) Library: The Home of Knowledge. Enugu: HRV Publishers. 
Rajkoomar, M. (2012) Essay on the Importance of a Library. Retrieved August 27 from http://www.publishingourarticles.net/knowledge-hub/essay/an-essay-on-the-importance-of-a-library.html 